\title{
PERIODISTAS Y PROFESORES COMO TRANSMISORES DE CONOCIMIENTO
}

\section{JOURNALISTS AND TEACHERS AS KNOWLEDGE TRANSMITTERS}

\section{AUTORA}

\section{Elvira Calvo Gutiérrez}

Facultad de Ciencias de la Información. Universidad Complutense de Madrid (España) ecalvogu@ccinf.ucm.es

\section{RESUMEN}

La sociedad de la información está saturada. Las nuevas tecnologías han provocado un exceso informativo que nos desborda. Los medios de comunicación se juegan su futuro. En este contexto, se hace necesaria una revisión de su función social. La Educomunicación promueve una educación de los medios, en la escuela pero también en la sociedad; con especial referencia a la comunicación audiovisual debido a la importancia e influencia que adquiere en la llamada iconosfera. La información, cuyo objetivo final es el conocimiento, es compartida por los profesionales de la comunicación y la educación. La televisión, como poderoso instrumento de socialización y culturalización, puede, y debe, servir para fomentar una sociedad activa, crítica y participativa.

\section{PALABRAS CLAVE}

Educomunicación - Medios - Educación - Comunicación - Televisión.

\section{ABSTRACT}

Information Society is saturated. New technologies have provoked an informative excess that exceeds us. Mass media play his future. In this context, it becomes necessary a review of its social function. Educommunication promotes an education 
of the social media, in the school but also in the society; with special reference to the audio-visual communication due to the importance and influence that it acquires in the called ionosphere. Information, which final aim is the knowledge, is shared by communication and education professionals. Television, like powerful tool of socialization and acculturation can, and must, serve to promote an active, critical and participative society.

\section{KEY WORDS}

Media Literacy - Social Media - Education - Communication - Television.

\section{ÍNDICE}

1. Introducción: Educomunicación.

2. El poder educativo de los medios.

3. Educación y televisión.

4. Conclusiones.

5. Bibliografía.

6. Webgrafía

\section{Introducción: Educomunicación}

El concepto de Educomunicación o educación en medios, también llamada media literacy en el ámbito anglosajón, es una disciplina que defiende la integración de la enseñanza sobre y con los medios de comunicación en el currículo escolar. La disciplina surge de las teorías de la Comunicación y la Educación y su objetivo es educar en la recepción crítica de los medios de comunicación, de manera que el ciudadano sea consciente de cómo se construyen los mensajes que recibe para 
tomar decisiones más razonadas. Por otro lado, también forma para la producción crítica, para que el ciudadano pueda participar de la sociedad de una manera libre y responsable elaborando sus propios mensajes y participando de la vida democrática desde su propia autonomía personal.

La educomunicación no se opone al consumo mediático y huye de los presupuestos reaccionarios que pretenden una educación de espalda a los medios. Al contrario, reconoce la presencia e influencia de los medios en la vida cotidiana y pretende educar sobre ellos y con ellos, tomándolos como fuente de material de interés para el aula así como objeto de estudio en sí mismos.

Pero, ¿por qué educar en comunicación? Los teóricos del campo de la educomunicación observan cuatro razones fundamentales: por la influencia creciente de los medios en el devenir político, por la alta tasa de consumo de medios y la saturación informativa, por la capacidad que tienen de influir en nuestro modo y estilo de vida y por la importancia creciente de la comunicación visual. Por todo ello, hoy más que nunca, se impone una educación sobre los medios y con los medios.

\section{El poder educativo de los medios}

En el Congreso Comunicación y Educación: propuestas para construir un futuro. XI Congreso Nacional de Estudiantes de Comunicación Social, celebrado este año en Cartagena de Indias (Colombia, mayo de 2006), la profesora Tíscar Lara afirmaba que no hay Comunicación sin Educación, como no hay Educación sin Comunicación. Ambos campos del desarrollo humano trabajan con la información con el objeto de ser transformada en conocimiento. En este artículo, se parte de la observación de un cierto paralelismo en los procesos de cambio que tanto la Comunicación, como la Educación, están experimentando en su adaptación a la Sociedad de la Información. 


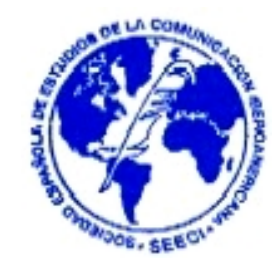

Nadie discute la importancia de los medios de comunicación en la sociedad actual. Nos encontramos inmersos en una sociedad mediática y nuestro estilo de vida convive con los mensajes que nos transmiten los medios de comunicación. De la misma forma, hablar de medios de comunicación implica abarcar un abanico de posibilidades muy amplio: televisión, radio, Internet, publicaciones impresas de todo tipo.

Los medios de comunicación de masas constituyen un aparato de socialización muy importante: influyen en nuestras ideas, hábitos y costumbres. Algunos expertos incluso llegan a afirmar que la cantidad de información comunicada por la prensa, las revistas, las películas, la televisión y la radio, excede en gran medida al volumen de información que llega a través de la enseñanza y los contenidos que se transmiten en la escuela.

Esto convierte a los medios de comunicación en una herramienta educativa muy poderosa, aunque educar no sea su finalidad última. Educar a través de los medios es un complemento. Los medios de comunicación se han vuelto imprescindibles en el proceso educativo, ya que forman parte del material didáctico utilizado con frecuencia en el aula. Quizás Internet es el medio que se ha incorporado más rápidamente a la educación.

La relación entre educación y medios de comunicación es un tema de debate interesante para los profesionales, al tratarse de dos temáticas vinculadas estrechamente. Ambas comparten una misma materia, la información. Y ambas pretenden el mismo objetivo: conocimiento (educar/informar). Esta relación establece un paralelismo entre el maestro y el periodista.

En el plano docente, hace tiempo que los profesores han tomado conciencia de la importancia de los medios de comunicación en las aulas en la educación de futuras generaciones, para que desarrollen una conciencia crítica ante la abundancia de 
información. En la actual sociedad del conocimiento, existen muchos canales de comunicación y, aunque a menudo es difícil reaccionar ante tanta información, los educadores se han esforzado para crear materiales para trabajar en el aula. Asimismo, han elaborado muchas teorías sobre su función como profesionales en la educación para la comunicación.

En países como Reino Unido y Canadá, los programas docentes incluyen formación sobre los medios de comunicación en las aulas. En España, esta iniciativa sigue correspondiendo a maestros y profesores que, a título particular, deciden trabajar el tema con sus alumnos. Así encontramos periódicos escolares, vídeos realizados por los propios alumnos, programas radiofónicos, etc. Estas iniciativas tienen como objetivo ampliar las capacidades de análisis activo y crítico de la oferta informativa. A la vez, se intenta familiarizar al alumnado con los códigos propios de los medios y enseñarle cómo se selecciona la información que aparece en los periódicos, de qué forma se nos presentan los contenidos y tratamientos de la información en función del medio, sus propósitos implícitos y explícitos. En definitiva, se trata de propuestas que ayuden a los usuarios de los medios a ser críticos con ellos, a seleccionar lo que les interesa, y a hacer un buen uso de toda la información que tienen a su disposición.

Pero ¿son los periodistas conscientes de su papel educador? ¿Son conscientes los medios de comunicación de la repercusión que tienen en la educación? Las nuevas tecnologías han traído una inmediatez informativa que ha hecho olvidar a los profesionales su responsabilidad en la educación, como servicio público y como canal influyente en la sociedad a la que sirven. Es esta función social la que el periodismo del siglo XXI debe recuperar. Establecer una relación fluida entre educación y comunicación mejorará ambas disciplinas.

Vivimos inmersos en la abundancia informativa. La sociedad de la información está saturada. La censura de épocas pasadas es hoy la saturación informativa. Es abusiva 


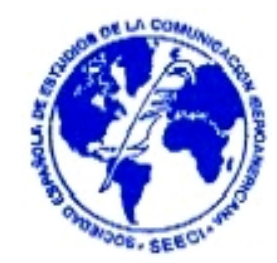

la presencia de los medios de comunicación en los más variados espacios de nuestra vida. Prensa, radio, televisión e Internet invaden nuestro entorno. Hemos pasado de la logosfera, de la supremacía de la palabra, a la iconosfera, donde impera la imagen. La comunicación audiovisual se ha convertido en una poderosa herramienta de conocimiento, de socialización, ¿de aturdimiento?

La mayoría de las veces no somos más que meros receptores pasivos. No nos planteamos reaccionar ante las manipulaciones ideológicas y extorsiones que la que la comunicación audiovisual lleva consigo y nos impone. Somos conscientes de las propiedades que los medios como lenguajes expresivos, de enorme influencia social, tienen para el desarrollo de las personas y de la propiedad humana. Estos lenguajes hacen uso de unos códigos de lectura y escritura que es imprescindible conocer y dominar para poderlos entender, interpretar y utilizar. Nuestra sociedad y nuestra escuela tienen la apasionante tarea de incorporar la función educativa en la vida social y docente, de enseñar a interpretar y crear el lenguaje audiovisual para superar el analfabetismo icónico.

Los medios de comunicación enseñan. Este fenómeno lo llamamos alfabetización mediática. Es importante que los ciudadanos y los alumnos comprendan mejor la dimensión económica y cultural de los medios de comunicación y que se produzca un debate sobre la importancia que tiene para la economía europea disponer de medios de comunicación fuertes y competitivos a nivel mundial y que ofrezcan pluralismo y diversidad cultural. Los medios de comunicación pueden tener un papel en el diálogo cultural, la inclusión social y la cohesión comunitaria, fomentar la tolerancia y el pluralismo en sociedad. Constituyen un medio efectivo para reforzar la inclusión social y la participación ciudadana, convirtiéndoles en participantes activos de la sociedad e intervenir en debates sobre asuntos importantes. Los medios también pueden establecer un vínculo entre los ciudadanos y los servicios públicos. 
Como señala Tiscar Lara, la relación entre educación y comunicación ha adquirido preeminencia social y cultural en el último medio siglo gracias al papel estratégico de las tecnologías de la información y la comunicación en la vida contemporánea hasta el punto de hablarse de sociedad de la información, sociedades del conocimiento, sociedad del aprendizaje, sociedad en red y otras tantas denominaciones en las que se implican diversas concepciones de mundo. Hablamos de nuevos modelos de vida y de nuevos métodos de enseñanza, donde el esquema de roles tradicionales periodista/maestro, ciudadanos/alumnos, cambia. Es necesaria la figura del periodista verificador frente al periodista seleccionador de noticias, porque ahora es la audiencia quien elige qué, cuándo y dónde informarse. Del mismo modo, se generaliza la figura del maestro tutor, como guía de conocimiento, frente al maestro docente. Ahora todos somos emisores y receptores, dependiendo de nuestra situación en el proceso comunicativo. Somos prosumer (productor y consumidor) y emirec (emisor y receptor).

Situar al ciudadano como eje de la sociedad supone crear una verdadera democracia participativa y superar el despotismo ilustrado de los poderes económicos, políticos y mediáticos que mantienen su poder gracias a la pasividad atribuida a las figuras de consumidor, público y audiencia. Se trata de pasar de una comunicación/educación para el público pero sin el público a una comunicación/educación para el ciudadano con el ciudadano.

\section{Educación y televisión}

La calidad de la televisión se ha convertido en un debate constante. Los usos y efectos televisivos dividen a los expertos. El investigador italiano Umberto Eco los dividió en 1965 en dos grupos (Eco, 1965):

- Los apocalípticos, que critican el funcionamiento de la Televisión y afirman que es un medio que favorece la manipulación, la alienación y da lugar a la 
imitación casi simiesca. Desde los contenidos emitidos por televisión, critican la violencia, sexo, lenguaje soez, reproducción de estereotipos negativos de clase, raza y sexo con frecuencia habituales en las parrillas de la pequeña pantalla. Las críticas apocalípticas provienen de intelectuales de procedencia muy diversa tales como educadores; sociólogos; filósofos, artistas, asociaciones de consumidores y amas de casa, sindicatos, ONGs y congregaciones religiosas que han acuñad el concepto de "telebasura" para denunciar el amarillismo y el sensacionalismo con que se tiñe la pantalla actual. Los debates son candentes en torno a la relación de la infancia con la pequeña pantalla. Mucho se ha escrito sobre la influencia negativa de la televisión en la formación de los pequeños y muchos informes vincularon la delincuencia y el vandalismo presentes en nuestras sociedades con las imágenes televisadas. La resolución de conflictos apelando a la violencia, el incentivo al consumo desde los programas infantiles 0 el inculcar en los menores estereotipos sexistas son con frecuencia materia de condena por parte de educadores, padres y legisladores.

- Los integrados, que observan a la cultura de masas, en general, y a la televisión, en particular, como un elemento democratizador y positivo. Son profesionales del medio, periodistas e intelectuales que señalan que la televisión es un fantástico medio de comunicación que forma parte del sistema nervioso de las sociedades contemporáneas. Defienden la televisión y sus contenidos, defendiendo los gustos masivos y populares, puesto que la cultura de masas de nuestros días es la cultura genuina de la sociedad. En este sentido, indican que la televisión es "una ventana al mundo" y un formidable instrumento de socialización que sirve de elemento de cohesión social y de satisfacción personal al poner al alcance de cualquiera entretenimiento, información y cultura. Los integrados consideran que la Televisión es uno de los mecanismos básicos de socialización y una de las principales fuentes de información de los niños. Además, señalan que la influencia de la televisión en la conducta del niño depende, en gran medida, 
del entorno familiar y social en que se desarrolla el pequeño televidente. Señalan que la televisión, y la irrefutabilidad de sus imágenes, enseñan a considerar la política y la información como bienes consumibles. Lejos de denunciar la función mediadora de la televisión y la construcción de la realidad de cada día, sus defensores apelan la objetividad de las crónicas y los reportajes televisivos.

El profesor Raúl Rodríguez Ferrándiz, especialista en semiótica de la comunicación de masas, explica que las defensas de la televisión pasan por proclamar los efectos benéficos del consumo televisivo y por la audiencia astuta y activa capaz de reapropiarse y de manipular los mensajes que la televisión pone a su alcance. La televisión elabora los verdaderos discursos pedagógicos que circulan hegemónicamente por el país y que el medio nos tiene al corriente de las amenazas que nos rodean, nos informa sobre el cáncer, el alcoholismo, las enfermedades de transmisión sexual, nos advierte de las precauciones que debemos tomar en las carreteras, en las playas. La televisión promueve un individualismo narcisista, pero tolerante, de principios fluctuantes y moralidad esencialmente abierta. Por ejemplo, en la representación social e ideológica de los valores 'políticamente correctos' que trasmiten las series de ficción. De esta manera, los medios, entre ellos la televisión, han conseguido completar, en un ciclo temporal más corto, los valores pedagógicos y de socialización que emanan a medio plazo de otras instancias de socialización y de transmisión del saber, como la familia o la escuela (Rodríguez Ferrándiz, 2001, pp. 94-97).

Frente a los apocalípticos e integrados, actualmente se reconoce una tercera una corriente de pensamiento que, en los últimos años, viene revalorizando la figura del televidente activo. Es decir, un televidente capaz de analizar críticamente los productos audiovisuales ofertados y de dar a los mismos, significados funcionales para sus necesidades. 
No hay que olvidar que son muchos los profesionales que utilizan las posibilidades del medio para hacer llegar la labor formativa -el colegio, el instituto, la academia o la Universidad- a lugares inaccesibles de nuestro planeta a los que es mucho más fácil - o económicamente viable- trasladar una antena y un televisor, que levantar un edificio y dotarlo de los materiales y personal necesarios. Algunos forman parte de los llamados medios alternativos o del tercer sector de la comunicación, que llevan años trabajando en este sentido y que aún están a la espera de un espaldarazo legislativo que les dote de personalidad jurídica.

Alternativos o no, lo cierto es que la oferta de canales dedicados a la formación va en aumento y constituye una alternativa eficaz a la enseñanza presencial cuando ésta, por miles de motivos, no resulta accesible. Hoy, ya nadie tiene dudas acerca de que la televisión es uno de los principales agentes de socialización. J unto a la familia y a la educación formal o reglada (educación primaria y secundaria), la televisión es una de las principales fuentes de conocimiento y de autoridad en las sociedades occidentales. A través de sus contenidos, el medio televisivo difunde modelos de vida, normas de comportamiento y valores sociales a los televidentes de todas las edades y de todas partes del mundo.

En las últimas décadas, la irrupción de la televisión por cable y de las plataformas de televisión vía satélite directa al hogar ha propiciado el crecimiento exponencial de la cantidad de horas de programación ofertadas. Si bien es cierto que, en su mayor parte, éstas están dedicadas a ampliar una oferta de contenidos basada en el ocio y el entretenimiento (deportes y películas principalmente), también lo es que los espacios dedicados a la formación y a la educación se han incrementado levemente y los documentales se han erigido en el formato estrella (Canal Historia, National Geographic). Afortunadamente, y aunque no ocupen la franja del prime time, proliferan los programas divulgativos, culturales y educativos con especial atención a la infancia, sobre todo en las televisiones públicas, los canales universitarios, la enseñanza de idiomas a través de la televisión. En España y en otras muchas partes 
del mundo. En este sentido, cabe destacar la labor de ATEl (Asociación de las Televisiones Educativas y Culturales I beroamericanas), una organización sin ánimo de lucro, creada en 1992 para gestionar la Televisión Educativa y Cultural Iberoamericana (TEIb), del Programa de Cooperación de las Cumbres Iberoamericanas de Jefes de Estado y de Gobierno. Su misión es contribuir al desarrollo de la educación, la ciencia y la cultura en Iberoamérica, mediante la utilización de la televisión y demás tecnologías de la información y comunicación.

Por otra parte, Internet en su versión banda ancha se presenta como la última promesa que permitirá a la producción, ya no audiovisual, sino multimedia, vencer el obstáculo de la distancia para llegar a individuos, empresas y centros de formación con contenidos al servicio de los sistemas de educación reglada, la formación permanente y el reciclaje profesional.

\section{Conclusiones}

Vivimos inmersos en la abundancia informativa. La sociedad de la información está saturada y la comunicación, especialmente audiovisual, se ha convertido en una poderosa herramienta de conocimiento y de socialización pero también de aturdimiento.

Se hace necesario situar al ciudadano como eje de la sociedad parea crear una verdadera democracia participativa y superar el despotismo ilustrado de los poderes económicos, políticos y mediáticos que mantienen su poder gracias a la pasividad de los consumidores, el público, la audiencia. Se trata de pasar de una comunicación/educación para el público, pero sin el público, a una comunicación/educación para el ciudadano y con el ciudadano.

Esta propuesta de la Educomunicación, de la educación en medios, de la Media Literacy, enriquecerá a todos: 
- Los medios de comunicación social serán mas creíble si asumen una responsabilidad pedagógica con respecto a los ciudadanos que se fundamenta en su propia razón de ser como servicio público. Este enfoque didáctico del periodismo, apenas desarrollado y ni siquiera reconocido en la mayor parte de los casos, entiende que ha de contribuir a la formación de un ciudadano crítico y plenamente formado para la participación democrática. Cuanto más explicativo sea el periodismo sobre sus métodos, sobre sus principios, sobre su funcionamiento interno; más transparente y, por tanto, creíble será para el ciudadano. En la Sociedad de la Información, este aspecto de los medios de comunicación se hace aún más necesario, una vez que su papel de seleccionador privilegiado es destronado y ha de ayudar al ciudadano en el acceso, verificación y producción de la información desde una postura integradora y conciliadora; invitando a las nuevas voces a participar del proceso comunicativo.

- La escuela tendrá un enfoque adaptado a los nuevos tiempos, enseñando a los jóvenes no sólo a obtener la información que desean, sino a generar sentido de la misma. Con la continuada emergencia de nuevas tecnologías, el aprendizaje se centrará menos en conocimientos memorísticos y mucho más sobre aprendizaje de los caminos que conducen al conocimiento.

- Los ciudadanos serán capaces de extraer y de elaborar la información que consideren necesaria para su desarrollo social, si los medios contribuyen a generar sentido dentro de la sobreabundancia de información. Deben compartir las excelencias del método periodístico y desarrollar una mente crítica y activa que mejore el modo de relacionarse en sociedad.

- Los estudiantes aprenderá a aprender y podrán seguir construyendo su conocimiento en todas las etapas de la vida, desarrollando una conciencia participativa. Han de formarse en la capacidad del aprendizaje autónomo y afrontar de forma crítica la nueva era de la iconosfera que les ha tocado vivir. 
Los profesionales de la comunicación deben asumir su labor pedagógica en el quehacer diario. La irrupción de la televisión por cable y de las plataformas de televisión vía satélite están propiciado la oferta de espacios dedicados a la formación y a la educación. Encomiable es la labor de ATEI, la Asociación de las Televisiones Educativas y Culturales Iberoamericanas que gestiona la Televisión Educativa y Cultural I beroamericana (TEIb).

Por otra parte, Internet en su versión banda ancha se presenta como la última promesa que permitirá a la producción, ya no audiovisual, sino multimedia, vencer el obstáculo de la distancia para llegar a individuos, empresas y centros de formación con contenidos útiles para el periodismo y la comunicación.

\section{Bibliografía}

ECO, Umberto (1965): Apocalípticos e integrados. Lumen. Barcelona.

RODRÍGUEZ FERRÁNDIZ, R. (2001): Apocalypse Show. Biblioteca Nueva. Madrid.

\section{Webgrafía}

Texto presentado en el Congreso Comunicación y Educación: propuestas para construir futuro. XI Congreso Nacional de Estudiantes de Comunicación Social. 


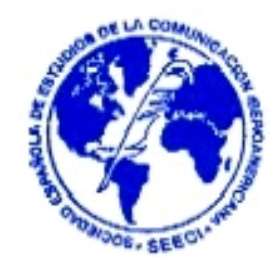

Cartagena de Indias, Colombia. Mayo 2006. Disponible en: http://tiscar.com/2006/05/14/comunicacion-y-educacion/. Consultado el 03-08-2006. Media Televisión. Disponible en:

http://recursos.cnice.mec.es/media/television/bloque10/index.html. Consultado el 07-08-2006.

Plan de empresa: Produccions S.L. Disponible en: www.ub.edu/empresarials/ec/pdfs/4461-ESP-planmk_mp_av.pdf. Consultado el 2307-2006.

Raúl Rodríguez Ferrándiz. Profesor y autor de un libro sobre la televisión. Disponible en: www.ua.es/dossierprensa/2001/07/31/6.html. Consultado el 20-08-2006. ¿Qué es ATEI? Disponible en: www.atei.es/atei/pages/inicio.asp. Consultado el 2508-2006. 